\title{
Obstructed labour in a Nigerian tertiary health facility: a mixed-method study
}

\author{
Akaninyene Eseme Ubom ${ }^{1 *}$, Omotade Adebimpe Ijarotimi ${ }^{1,2}$, Ifeoluwa Emmanuel Ogunduyile ${ }^{3}$, \\ Ayobami Omilakin ${ }^{4}$, Solomon Nyeche ${ }^{5}$, Emeka Philip Igbodike ${ }^{6}$, \\ Ogunjide Olakunle Emmanuel7, Ernest Okechukwu Orji ${ }^{1,2}$, John Igemo Ikimalo ${ }^{5}$, \\ Adebanjo Babalola Adeyemi ${ }^{1,2}$
}

\author{
${ }^{1}$ Department of Obstetrics, Gynaecology, and Perinatology, Obafemi Awolowo University Teaching Hospitals Complex, \\ Ile-Ife, Osun state, Nigeria \\ ${ }^{2}$ Department of Obstetrics, Gynaecology, and Perinatology, Faculty of Clinical Sciences, College of Health Sciences, \\ Obafemi Awolowo University, Ile-Ife, Osun state, Nigeria \\ ${ }^{3}$ University Hospitals of Derby and Burton NHS Foundation Trust, United Kingdom \\ ${ }^{4}$ Royal Wolverhampton NHS Trust, United Kingdom \\ ${ }^{5}$ Department of Obstetrics and Gynaecology, University of Port Harcourt/University of Port Harcourt Teaching Hospital, \\ Port Harcourt, Rivers state, Nigeria \\ ${ }^{6} \mathrm{St}$ Georges Hospital Memorial Centre, Lagos state, Nigeria \\ ${ }^{7}$ Department of Obstetrics and Gynaecology, University of Ilorin Teaching Hospital, Ilorin, Kwara state, Nigeria
}

Received: 26 May 2021

Accepted: 30 June 2021

\section{*Correspondence:}

Dr. Akaninyene Eseme Ubom,

E-mail: akaninyeneubom@oauthc.com

Copyright: () the author(s), publisher and licensee Medip Academy. This is an open-access article distributed under the terms of the Creative Commons Attribution Non-Commercial License, which permits unrestricted non-commercial use, distribution, and reproduction in any medium, provided the original work is properly cited.

\begin{abstract}
Background: Obstructed labour remains a leading cause of maternal and perinatal mortality and morbidity in subSaharan Africa. This study aimed to determine the incidence, causes, complications and outcomes of obstructed labour at the Obafemi Awolowo University Teaching Hospitals Complex (OAUTHC), Ile-Ife, Osun state, Nigeria.

Methods: A mixed methods approach was employed for this study. A 10-year retrospective review of all cases of obstructed labour managed at the OAUTHC, between January 1, 2008, and December 31, 2017, was done. Ten in-depth interviews were conducted for some selected patients. The quantitative data was analysed using SPSS version 24, while the qualitative data was analyzed with NVivo version 12.

Results: The incidence of obstructed labour was $1.99 \%$. Most of the patients were unbooked $(217,90.4 \%)$, primigravid $(138,57.5 \%)$, and either had no formal or only primary/secondary education $(120,50 \%)$. Cephalopelvic disproportion (CPD) was the commonest cause of obstructed labour $(227,94.6 \%)$. The most common maternal complication was wound infection $(48,20 \%)$. There were three maternal deaths, giving a case fatality rate of $1.25 \%$. The most common foetal complication was birth asphyxia $(85,34.7 \%)$. The perinatal mortality rate was $18.8 \%$. From the qualitative arm of the study, reasons given by parturients who suffered obstructed labour, for avoiding hospitals for delivery, included religion, finance, fear of hospitals, faith/belief in mission homes/maternity houses, and proximity.

Conclusions: Obstructed labour remains an important obstetric problem in our environment, contributing significantly to the burden of maternal and perinatal mortality and morbidity.
\end{abstract}

Keywords: Maternal morbidity, Maternal mortality, Obstructed labour, Perinatal morbidity, Perinatal mortality, Nigeria 


\section{INTRODUCTION}

Labour is said to be obstructed when there is failure of progress of labour despite adequate uterine contractions, due to a mechanical factor, which if unrelieved, will lead to various maternal and/or foetal complications. ${ }^{1-3}$ Obstructed labour is an obstetric entity which is alien to developed countries but remains very prevalent in developing countries, where it contributes significantly to maternal and perinatal morbidity and mortality. ${ }^{4-6}$

Illiteracy, ignorance, poverty, belief in home deliveries under the supervision of traditional birth attendants (TBAs), lack of good transportation systems, ill-equipped health facilities, poor access to available health facilities, poor emergency obstetric care services, and aversion to surgery, are some of the factors responsible for the high incidence of obstructed labour in developing countries. ${ }^{5,7}$ On the other hand, optimum obstetric and social services have made obstructed labour virtually non-existent in the developed world. ${ }^{5}$

Obstructed labour accounts for about $8 \%$ of all maternal deaths and $39 \%$ of all obstetric admissions in developing countries. $^{1,3}$ In Nigeria, the reported incidence varies between $0.9 \%$ and $6.9 \% .^{4-9}$ It occurs more frequently amongst young, poorly literate, unbooked, nulliparous women, of lower social class. ${ }^{10}$ The commonest cause is cephalopelvic disproportion (CPD), which could arise from a contracted maternal pelvis, foetal macrosomia, or foetal malposition. ${ }^{1,11,12}$ A contracted maternal pelvis could be seen in teenagers, or be the result of poliomyelitis, sickle cell disease, uncontrolled childhood infections, and childhood malnutrition, all of which cause stunting of growth. ${ }^{9,12}$ Other causes of obstructed labour include foetal malpresentation/abnormal lie, congenital malformations in the foetus (such as hydrocephalus), impacted pelvic tumour, cervical or vaginal stenosis, and a rigid perineum. ${ }^{1,11,12}$

Complications of obstructed labour are myriad. Prolonged uterine contractions in the presence of inadequate calorie intake in obstructed labour could result in metabolic acidosis. ${ }^{12}$ Hypertonic uterine contractions in the face of an obstruction can cause uterine rupture, which could be complicated by maternal haemorrhage, haemorrhagic shock, and death. ${ }^{3,10,12}$ Massive maternal hamemorrhage could result in coagulation failure, hysterectomy, and Sheehan's syndrome, with possible long term complications of secondary amenorrhoea and secondary infertility. ${ }^{12}$ Vesicovaginal fistula (VVF) is another very devastating complication of obstructed labour. ${ }^{10,12}$ Prolonged labour with prolonged rupture of foetal membranes may be complicated by puerperal sepsis, septic shock, and death. ${ }^{3,10,12}$ Traumatic delivery could cause genital tract lacerations. ${ }^{10,12}$ Other maternal complications include complications of Caesarean delivery and anaesthesia. ${ }^{12}$ Foetal complications include foetal distress, intrauterine foetal death, stillbirth, neonatal asphyxia, neonatal sepsis, and death. ${ }^{12}$ Perinatal mortality is mainly due to asphyxia. ${ }^{3,10}$

Principles of management of obstructed labor include correction of fluid and electrolyte derangements, control of infection/antibiotic prophylaxis, and immediate relief of obstruction. ${ }^{12}$ The management of cases where the foetus is alive requires an emergency caesarean section, while destructive operations may be done in the case of a dead foetus. ${ }^{10,12}$ Post-operatively, the bladder is rested by prolonged catheterization to prevent fistula formation. ${ }^{12}$

The aim of this study was to determine the incidence, causes, complications and outcomes of obstructed labour at the OAUTHC, Ile-Ife, Osun state, Nigeria, so as to formulate appropriate strategies and interventions for its prevention. The qualitative aspect of the study was employed to give first-hand knowledge into the possible reasons why women who suffer obstructed labour avoid hospitals for delivery.

\section{METHODS}

This was a mixed-methods study. The quantitative aspect was a 10-year retrospective review of all cases of obstructed labour managed at the OAUTHC, Ile-Ife, Osun state, Nigeria, between January 1, 2008, and December 31, 2017. The medical records of all women managed for obstructed within the study period were retrieved from the medical records department of the hospital, and relevant data extracted using a purpose-designed proforma. Data extracted included the sociodemographic characteristics of the women, cause of obstructed labour, mode of delivery, maternal and foetal outcomes and complications. Independent variables included age, parity, booking status, level of education, and social class. Social class was determined using the woman's level of education and her husband's occupation, according to the recommendation of Olusanya et al. ${ }^{13}$ Dependent or outcome variables were cause of obstructed labour, type of intervention, foetal characteristics, perinatal outcomes/complications, and maternal complications. The data obtained was analysed using the Statistical Package for Social Sciences (SPSS) version 24, and presented in tables and percentages. Associations between categorical independent variables and outcome variables were compared where applicable, using chi-square with level of significance set at $<0.05$.

For the qualitative aspect of the study, in-depth interviews (IDIs) with women who had suffered obstructed labour were conducted with an interview tool that included openended questions that sought the respondents' reasons for patronizing the mission houses/maternity homes, where their labours became obstructed. Ten IDIs were conducted for some selected cases between January-March 2021. Informed consent was obtained from the respondents before the interviews. The qualitative aspect of the data was analyzed with NVivo version 12 . The data was transcribed, coded and categorized. Themes were developed and some verbatim quotes were reported to 
provide insight into reasons for avoiding hospital for delivery.

\section{RESULTS}

\section{Incidence and sociodemographic characteristics of parturients}

Within the 10-year study period, there were 12,044 deliveries at the OAUTHC. Of these, 240 were complicated by obstructed labour, giving an incidence of obstructed labour of $1.99 \%$ (19.9 per 1,000 deliveries).

The maternal ages ranged between 14 and 41 years, with a mean age of $26.8 \pm 5.7$ years, and modal age of 25 years. Eighteen, $7.5 \%$, of the affected parturients were teenagers. Most of the women were unbooked (217, 90.4\%), nulliparous $(138,57.5 \%)$, either had no formal or only primary/secondary education $(120,50 \%)$, and were of low/middle socioeconomic class $(128,53.3 \%)$. These findings are shown in Table 1.

Table 1: Sociodemographic characteristics of patients with obstructed labour at theOAUTHC, $(n=240)$.

\begin{tabular}{|c|c|c|}
\hline Characteristic & Frequency & $\%$ \\
\hline \multicolumn{3}{|l|}{ Ages (Years) } \\
\hline$<20$ & 18 & 7.5 \\
\hline $20-29$ & 134 & 55.8 \\
\hline $30-39$ & 82 & 34.2 \\
\hline$\geq 40$ & 6 & 2.5 \\
\hline \multicolumn{3}{|l|}{ Parity } \\
\hline Nullipara & 138 & 57.5 \\
\hline 1 & 41 & 17.1 \\
\hline 2 & 30 & 12.5 \\
\hline 3 & 13 & 5.4 \\
\hline 4 & 11 & 4.6 \\
\hline$\geq 5$ & 7 & 2.9 \\
\hline \multicolumn{3}{|l|}{ Booking status } \\
\hline Booked & 23 & 9.6 \\
\hline Unbooked & 217 & 90.4 \\
\hline \multicolumn{3}{|l|}{ Educational status } \\
\hline No formal education & 3 & 1.3 \\
\hline Primary level education & 37 & 15.4 \\
\hline $\begin{array}{l}\text { Secondary level } \\
\text { education }\end{array}$ & 80 & 33.3 \\
\hline Tertiary level education & 36 & 15 \\
\hline${ }^{*}$ Unspecified & 84 & 35 \\
\hline \multicolumn{3}{|l|}{ Social class } \\
\hline High & 24 & 10 \\
\hline Middle & 61 & 25.4 \\
\hline Low & 67 & 27.9 \\
\hline ***Unspecified & 88 & 36.7 \\
\hline Total & 240 & 100 \\
\hline
\end{tabular}

\section{Causes of obstructed labour}

The most common cause of obstructed labour in this study was cephalopelvic disproportion (CPD) (227, 94.6\%). Deep transverse arrest was implicated in 2, $0.8 \%$, cases, while malpresentation was the cause in $11(4.6 \%)$ patients, out of which breech presentation represented 7 (2.9\%) cases, face presentation, $3(1.3 \%)$, and compound presentation, $1(0.4 \%)$.

All the parturients obstructed while labouring at mission houses/maternity homes.

Why do parturients patronize mission houses/maternity homes?

\section{Financial reasons}

Three of the 10 IDI respondents attributed their patronage of mission homes to lack of funds.

It was because of money. The maternity home is cheaper than the hospital, and I don't have money (Respondent 2, A 39-year-old para 5+0, who presented to the OAUTHC 29 days into the puerperium on account of secondary postpartum haemorrhage. She had laboured for 4 days in a mission house in Ilesa Osun state (where she had also received pregnancy care), before being referred to a private hospital, where she eventually had an emergency Caesarean section delivery, and was delivered of a male macerated stillbirth).

\section{Religious reasons}

One of the 10 IDI respondents volunteered that she had gone to a maternity home for prayers.

I went for prayers. I was afraid of having a complication in pregnancy, so I decided to go to a maternity home, where they combine prayers with pregnancy care, unlike the hospital, where they only offer pregnancy care (Respondent 1, A 27-year-old para 2+0, who had laboured for 12.5 hours at a maternity home before presenting to the OAUTHC in obstructed labour. She subsequently had emergency Caesarean delivery of a live female baby, with good Apgar scores).

\section{Faith/belief in mission houses/maternity homes}

Three of the 10 IDI respondents agreed that they went to mission homes/maternity houses because they had faith and belief in these places.

I am used to giving birth at the mission house. I have never given birth in a hospital. All my previous deliveries were at the mission house. That is why I went there again this time (Respondent 9, A 41-year-old-booked gravida 5, para $3^{+1}$, who presented to the OAUTHC in obstructed labour, having laboured for 39 hours at a mission house. She had 
emergency Caesarean delivery of a live female baby, with moderate birth asphyxia).

I don't have money. Plus that is where (the mission house) I gave birth to my first child. Also, many other people have been going to the same mission house and delivering safely without problems (Respondent 10, A 27-year-old gravida 2, para $1^{+0}$, who presented to the OAUTHC in obstructed labour, having been in labour for 12 hours at a mission house in Ilesa. She subsequently had emergency Caesarean section and was delivered of a live male baby with severe birth asphyxia).

\section{Fear of hospitals}

One of the IDI respondents demonstrated phobia for hospitals, and thus would rather go to a mission house.

I went to the maternity home because I don't have money. Also, I am afraid of hospitals (Respondent 7, A 20-yearold para $1^{+1}$, who presented on referral to the OAUTHC 3 days into the puerperium, with puerperal sepsis. She had had emergency Caesarean section at the referring hospital, after being in labour for 38 hours at home and two different maternity homes, and was delivered of a male stillbirth).

\section{Proximity}

One of the IDI respondents cited proximity as her reason for going to a maternity home.

It was because of the distance. The maternity home is closer to me than the nearest hospital (Respondent 4, A 35 -year-old para $4^{+0}$, who presented to the OAUTHC, about 45 minutes into the puerperium following prolonged obstructed labour secondary to footling breech presentation, after being in labour for 16 hours at a maternity home in Ilesa, before being verbally referred to the OAUTHC. She was delivered of a fresh female stillbirth).

\section{Interventions}

Lower segment Caesarean section was the mode of delivery in the majority of cases $(225,93.8 \%)$. Two, $0.8 \%$, women had subtotal hysterectomy, one, on account of primary postpartum haemorrhage and another, on account of uterine rupture. Fourteen, $5.8 \%$, women had repair of uterine rupture, out of which $13,5.4 \%$, were without bilateral tubal ligation (BTL), and 1, 0.4\%, with BTL. These are depicted in Table 2.

\section{Foetal characteristics}

Of the 245 babies ( 235 singletons and five twins) that were delivered, $157,64.1 \%$, were males while $88,35.9 \%$, were females. One hundred and eighty-six, $75.9 \%$, babies, were of normal birth weights, whereas $14,5.7 \%$, were either very low or low birth weight, and $18,7.3 \%$, were macrosomic. These foetal characteristics are shown in Table 3.

Table 2: Type of intervention $(n=240)$.

\begin{tabular}{|lll|}
\hline Intervention & Frequency & $\%$ \\
\hline $\begin{array}{l}\text { Lower segment C-section } \\
\text { Lower segment C-section, } \\
\text { re-exploration and subtotal } \\
\text { hysterectomy }\end{array}$ & 224 & 93.3 \\
\hline $\begin{array}{l}\text { Laparotomy and: } \\
\begin{array}{l}\text { Repair of uterine rupture } \\
\text { without tubal ligation }\end{array}\end{array}$ & 13 & 0.4 \\
\hline $\begin{array}{l}\text { Repair of uterine rupture } \\
\text { with tubal ligation }\end{array}$ & 1 & 5.4 \\
\hline $\begin{array}{l}\text { Subtotal hysterectomy } \\
\text { Total }\end{array}$ & 1 & 0.4 \\
\hline
\end{tabular}

Table 3: Foetal characteristics $(n=245)$.

\begin{tabular}{|lll|}
\hline Characteristics & Frequency & $\%$ \\
\hline Sex & & \\
\hline Male & 157 & 64.1 \\
\hline Female & 88 & 35.9 \\
\hline Birth weight (in kg) & & \\
\hline $1.0-1.49$ & 1 & 0.4 \\
\hline $1.5-2.49$ & 13 & 5.3 \\
\hline $2.5-3.99$ & 186 & 75.9 \\
\hline$\geq 4.0$ & 18 & 7.3 \\
\hline "Unspecified & 27 & 11 \\
\hline Total & 245 & 100 \\
\hline * Birth weights of 27 babies were not recorded. \\
\hline
\end{tabular}

\section{Foetal/perinatal outcomes and complications}

There were $207,84.5 \%$, live births, $38,15.5 \%$, stillbirths, and $8,3.3 \%$, early neonatal deaths, giving a perinatal mortality rate of $18.8 \%$ ( 188 per 1,000 births). All the early neonatal deaths were seen in babies who were asphyxiated at birth. The predominant foetal complication in this study was birth asphyxia. Eighty-five, 34.7\%, babies, had Apgar scores of $<7$ at one minute. These findings are as shown in Table 4

\section{Maternal complications}

Maternal complications were observed in $82,34.2 \%$, of the women. The most common maternal complications were wound infection $(48,20 \%)$, puerperal sepsis $(21,8.8 \%)$, primary postpartum haemorrhage $(15,6.3 \%)$, and uterine rupture $(15,6.3 \%)$. Uterine rupture occurred more commonly amongst parous women, compared with nulliparous women $(11,73.3 \%$ vs. $4,26.7 \%)$. Two, $0.8 \%$, women, had VVF. There were three maternal deaths, giving a case-fatality rate of $1.25 \%$. Puerperal sepsis and postpartum haemorrhage were implicated in the maternal deaths, with the former being the cause of death in one patient, the latter, the cause in another patient, and both, implicated in one patient. All the maternal deaths occurred 
in unbooked patients. These findings are summarized in Table 5.

Table 4: Perinatal outcomes and complications $(n=245)$.

\begin{tabular}{|lll|}
\hline Outcome/complication & Frequency & $\%$ \\
\hline Live birth & 207 & 84.5 \\
\hline Stillbirth & 38 & 15.5 \\
\hline Early neonatal death & 8 & 3.3 \\
\hline Birth asphyxia & & \\
\hline Mild birth asphyxia & 21 & 8.6 \\
\hline Moderate birth asphyxia & 35 & 14.3 \\
\hline Severe birth asphyxia & 29 & 11.8 \\
\hline
\end{tabular}

Table 5: Maternal complications $(n=240)^{*}$.

\begin{tabular}{|lll|}
\hline Complication & Frequency & $\%$ \\
\hline Wound infection & 48 & 20.0 \\
\hline Puerperal sepsis & 21 & 8.8 \\
\hline $\begin{array}{l}\text { Primary postpartum } \\
\text { haemorrhage }\end{array}$ & 15 & 6.3 \\
\hline Uterine rupture & 15 & 6.3 \\
\hline VVF & 2 & 0.8 \\
\hline Genital tract laceration & 2 & 0.8 \\
\hline Foot drop & 1 & 0.4 \\
\hline Acute renal failure & 1 & 0.4 \\
\hline Maternal death & 3 & 1.3 \\
\hline No complication & 158 & 65.8 \\
\hline${ }^{*}$ Multiple complications in some women, hence total $>240$
\end{tabular}

*Multiple complications in some women, hence total $>240$

\section{Relationship between maternal complications of obstructed labour and maternal and perinatal characteristics}

Though not significantly, women aged $\leq 30$ years were more likely than those $>30$ years to suffer complications of obstructed labour (36.8\% vs. $29.5 \%$; p=0.441). Also, women of low socioeconomic status were more likely than those of middle and high socioeconomic status to have complications, even though this relationship was not statistically significant $(40.3 \%$ vs. $27.9 \%$ vs. $16.7 \%$; $\mathrm{p}=0.248)$.

There was a statistically significant relationship between maternal complications of obstructed labour and parity, duration of admission, baby's birth weight, and perinatal complications. Nulliparous women were significantly less likely than parous women to suffer a complication $(29.7 \%$ vs. $40.2 \%$; $\mathrm{p}=0.004)$. Women who were admitted for $\geq 10$ days were significantly more likely than those admitted for $<10$ days to have suffered a complication $(36.5 \%$ vs. $17.2 \% ; \mathrm{p} \leq 0.001)$. Women who had low birth weight or macrosomic babies were significantly more likely than those whose babies were of normal birth weight to have suffered a complication of obstructed labour $(37.5 \%$ vs. $31.7 \%$; $\leq 0.001)$. Also, mothers whose babies had perinatal complications were significantly more likely than those of babies without perinatal complications to have also had a maternal complication of obstructed labour $(38.2 \%$ vs. $28.7 \% ; p \leq 0.001)$. These findings are summarized in Table 6.

Table 6: Relationship between maternal complications of obstructed labour and maternal and perinatal characteristics.

\begin{tabular}{|c|c|c|c|}
\hline \multirow[t]{2}{*}{ Characteristics } & \multicolumn{2}{|c|}{$\begin{array}{l}\text { Maternal } \\
\text { complications (\%) }\end{array}$} & \multirow{2}{*}{$\begin{array}{l}\mathbf{P} \\
\text { value }\end{array}$} \\
\hline & Yes & No & \\
\hline \multicolumn{4}{|l|}{ Age (years) } \\
\hline$\leq 30$ & $56(36.8)$ & $96(63.2)$ & \multirow{2}{*}{0.441} \\
\hline$>30$ & $26(29.5)$ & $62(70.5)$ & \\
\hline \multicolumn{4}{|c|}{ Socioeconomic status } \\
\hline High & $4(16.7)$ & $20(83.3)$ & \multirow{3}{*}{0.248} \\
\hline Middle & $17(27.9)$ & $44(72.1)$ & \\
\hline Low & $27(40.3)$ & $40(59.7)$ & \\
\hline \multicolumn{4}{|l|}{ Parity } \\
\hline Nulliparous & $41(29.7)$ & $97(70.3)$ & \multirow{2}{*}{0.004} \\
\hline Parous & $41(40.2)$ & $61(59.8)$ & \\
\hline \multicolumn{4}{|c|}{ Duration of admission (days) } \\
\hline$<10$ & $5(17.2)$ & $24(82.8)$ & \multirow{2}{*}{$<0.001$} \\
\hline$\geq 10$ & $77(36.5)$ & $134(63.5)$ & \\
\hline \multicolumn{4}{|c|}{ Baby's birth weight } \\
\hline $\begin{array}{l}\text { Normal birth } \\
\text { weight }\end{array}$ & $59(31.7)$ & $127(68.3)$ & \multirow[b]{2}{*}{$<0.001$} \\
\hline $\begin{array}{l}\text { Low birth } \\
\text { weight/foetal } \\
\text { macrosomia }\end{array}$ & $12(37.5)$ & $20(62.5)$ & \\
\hline \multicolumn{4}{|c|}{ Perinatal complications } \\
\hline Nil & $35(28.7)$ & $87(71.3)$ & \multirow[b]{2}{*}{$<0.001$} \\
\hline $\begin{array}{l}\text { Stillbirth/birth } \\
\text { asphyxia }\end{array}$ & $47(38.2)$ & $76(61.8)$ & \\
\hline
\end{tabular}

\section{DISCUSSION}

The incidence of obstructed labour in this study was $1.99 \%$, which is lower than the $6.9 \%$ reported by Fasubaa et al in a previous study in the same hospital, as well as the $4.0 \%$ and $3.2 \%$ reported in Gombe and Ilorin respectively. ${ }^{4,8,9}$ It is however similar to the incidence of $2 \%$ reported in both Uyo and Sokoto, but higher than the $0.9 \%$ reported in Port Harcourt. ${ }^{5-7}$ This could be due to the fact that the earlier study by Fasubaa et al, which was done between 1998 and 2000, and the studies in Illorin (1999) and Gombe (2003) might be a reflection of the previous trend of obstructed labour in Nigeria, while the more recent studies in Uyo (2006), Sokoto (2011), Port Harcourt (2012), and the index one, might represent its current trend. More so, compared to previously, better education and improved socioeconomic status of our women, as well as improvement/advancement in obstetric care may be contributory to the declining incidence of obstructed labour in the country.

The majority of patients in our study were between 20 and 29 years of age, and nulliparous with nearly a tenth of them being teenage primigravidae. Similar findings were 
reported in Uyo, Sokoto, and India. ${ }^{5,7,10}$. Our study found a positive correlation between obstructed labour complications and young maternal age. These findings may probably be explained by the fact that poverty, recurrent infections, malnutrition and early marriages, still endemic in our environment, may result in our females failing to attain their full developmental potentials before marriage, so that they start childbearing with contracted pelvis, resulting in a high incidence of obstructed labour among primigravidae in our environment. ${ }^{5,7,14}$

Other risk factors for obstructed labour identified in this study included unbooked status, low educational and socioeconomic status. These findings have been corroborated by other authors. ${ }^{1,5-7}$ Educational and socioeconomic status affect health-seeking behaviour of women, and therefore influence their reproductive health outcomes. ${ }^{15}$ It is difficult for women of low educational and socioeconomic status to make informed decisions about using health preventive and promotive services, such as antenatal care, or seek skilled attended delivery. ${ }^{16}$ More so, it cannot be over-emphasized that worldwide, antenatal care is generally acknowledged as a measure for the reduction of maternal and perinatal morbidity and mortality. ${ }^{5}$ It is therefore not unexpected that $90 \%$ of the women who suffered obstructed labour in our study were unbooked.

Cephalopelvic disproportion was the most common etiological factor for obstructed labour in this study, and lower segment $\mathrm{C}$-section was the most common mode of delivery. These findings have been corroborated by Kiran et al, as well as other authors. ${ }^{2,8,17}$ Cephalopelvic disproportion occurs more among primigravidae, who constituted the highest parturient group in this study. $2,5,18$ The reason for this is largely attributed to the fact that the primigravid pelvis is untested, and may also be underdeveloped. ${ }^{1,2} \mathrm{C}$-section is the treatment of choice when the foetus is alive, and most of the women in this study presented with live foetuses. ${ }^{5}$ Daniel and Singh reported that obstructed labour was the most common indication for emergency C-section in Sokoto. ${ }^{17}$

As similarly reported by Abasiattai et al, birth asphyxia was the most common neonatal complication of obstructed labour in this study. ${ }^{5}$ Three of the 10 affected women interviewed in our study delivered babies with moderate/severe birth asphyxia, while three had stillbirths. The perinatal mortality rate was $18.8 \%$. This is lower than the rates reported in studies in other parts of the country. ${ }^{5-}$ ${ }^{8}$ Several factors may be responsible for this difference, including intervals between onset of obstruction and presentation at the hospital, and between decision to deliver and delivery, amongst others.

The leading maternal complications of obstructed labour in this study were wound infection and puerperal sepsis. This is similar to findings in Ilorin and Gombe. ${ }^{8,9}$ Predisposing factors to infectious morbidity in obstructed labour include multiple unsterile vaginal examinations, and prolonged rupture of foetal membranes before presentation. Unbooked patients are also at increased risk of anaemia in the antenatal period, which predisposes them to infections in the postpartum period. More so, many of these women labour in unhygienic environments at home or the TBAs' before presenting at the hospital.

Other maternal complications of obstructed labour in this study were primary postpartum haemorrhage and uterine rupture. This study showed that parous women were more likely than nulliparous women to have a uterine rupture. This was also the finding of a study in Bangladesh. ${ }^{1}$ The primigravid uterus responds to obstructed labour with inertia, whereas the multi-gravid uterus responds to obstruction with hypertonic uterine contractions, which may result in a rupture. ${ }^{1,3}$ Two women in our study had VVF, one of the most devastating complications of obstructed labour, and a serious social calamity. The major cause of VVF in Nigeria is obstructed labour. ${ }^{19}$

There were three maternal deaths, giving a case-fatality rate of $1.25 \%$. This is similar to the $1.2 \%$ case-fatality rate reported in Uganda. $^{20}$ All the maternal deaths were unbooked cases. Maternal deaths occur more amongst unbooked than booked pregnant women. ${ }^{16}$ The causes of the maternal deaths were puerperal sepsis and primary postpartum haemorrhage. These were similarly reported as the causes of maternal death from obstructed labour in other studies in Sokoto, Bangladesh, and Pakistan. ${ }^{1,7,17}$

\section{CONCLUSION}

The findings of this study indicate that obstructed labour is still a common and significant cause of maternal and perinatal morbidity and mortality in our environment. A strength of this study is the innovation it brough into the body of knowledge on obstructed labour through the IDIs, which brought to the fore, the reasons why women who suffer obstructed labour avoid hospitals for delivery. A limitation of the study is its retrospective quantitative method. Despite this limitation, the study gave an insight into measures that can be instituted to reduce the incidence of obstructed labour and its associated maternal and perinatal morbidity and mortality in the developing world. Obstructed labour is largely preventable by a multilayered approach involving the patient, her family, the community, health care providers, and the government at all levels. Measures that promote education and economic empowerment of women need to be pursued vigorously, if the incidence of obstructed labour is to be reduced significantly. There is need for effective community-based enlightenment programmes on the importance of antenatal care and skilled attendance at birth. Such enlightenment programmes must also emphasize the dangers of teenage pregnancies and childhood marriages. The use of partograph for labour monitoring by all cadres of health personnel at all levels of health care, good quality, effective, and affordable antenatal care services, functional primary health care and prompt referral systems, as well as 
emergency obstetric care services will significantly reduce the incidence of obstructed labour.

\section{ACKNOWLEDGMENTS}

The authors would like to thank the patients who consented to being interviewed in the qualitative aspect of the study. We are also grateful to the medical records department of the OAUTHC, for allowing us access to the patients' case records used for the quantitative aspect of the study.

Funding: No funding sources

Conflict of interest: None declared

Ethical approval: The study was approved by the Institutional Ethics Committee

\section{REFERENCES}

1. Islam JA, Ara G, Choudhury FR. Risk Factors and Outcome of Obstructed Labour at a tertiary care Hospital. J Shaheed Suhrawardy Med Coll. 2012;4(2):43-6.

2. Kiran A, Singh RR, Sinha AN, Srinagar UI. A clinical study of 100 cases of Obstructed Labour and its Fetomaternal Outcome. JBLS. 2015;6(2):141-7.

3. Rizvi SM, Gandotra N. Maternofetal outcome in obstructed labour in a tertiary care hospital. Int $\mathrm{J}$ Reprod Contracept Obstet Gynaecol. 2015;4(5):141013.

4. Fasubaa OB, Ezechi OC, Orji EO, Ogunniyi SO, Akindele ST, Loto OM et al. Delivery of the impacted head of the fetus at caesarean section after prolonged obstructed labour: a randomized comparative study of two methods. J Obstet Gynaecol. 2002;22(4):375-8.

5. Abasiattai AM, Bassey EA, Etuk SJ, Udoma EJ. The Pattern of Obstructed Labour in Uyo, South-Eastern Nigeria. Trop J Obstet Gynaecol. 2006;23(2):146-9.

6. Jeremiah I, Nwagwu V. The pattern of obstructed labour among parturients in a tertiary hospital in southern Nigeria. Port Harcourt Med J. 2012;6(1):4455 .

7. Nwobodo EI, Ahmed Y. Obstructed labour: A public health problem in Sokoto, Nigeria. Sahel Med J. 2011;14(3):140-2.

8. Melah GS, El-Nafaty AU, Massa AA, Audu BM. Obstructed labour: a public health problem in Gombe,
Gombe state, Nigeria. J Obstet Gynaecol. 2003;23(4):369-73.

9. Aboyeji AP, Fawole AA. Obstructed labour in Ilorin, Nigeria: a one-year prospective study. Nig Med Pract. 1999;38:25-8.

10. Sharma P, Kumari K, Kanti V, Seth S. Obstructed Labour: A preventable tragedy but still a long way to go in developing countries. Int J Health Sci Res. 2015;5(9):99-104.

11. Ara A. Outcome of obstructed labour. JPMI. 2011;18(3):512-7.

12. Henok A, Asefa A. Prevalence of Obstructed Labour among Mothers Delivered in Mizan-Aman General Hospital, South West Ethiopia: A Retrospective Study. J Women's Health Care. 2015;4(5):250.

13. Olusanya O, Okpere EE, Ezimokhai M. Scoring system for social class. West Afr J Med. 1995;4:4.

14. Shaikh S, Shaikh AH, Shaik SAH, Isran B. Frequency of Obstructed Labour in Teenage Pregnancy. NJOG. 2012;7(3):37-40.

15. Agbata AT, Eze JN, Ukaegbe CI, Odio BN. A 4-year retrospective review of stillbirths at the Federal Teaching Hospital, Abakaliki, Southeast Nigeria. Afr J Med Health Sci. 2017;16:19-24.

16. Chigbu B, Onwere S, Kamanu CI, Aluka C, Okoro O, Adibe E. Pregnancy outcome in booked and unbooked mothers in South-Eastern Nigeria. East Afr Med J. 2009;86(6):267-71.

17. Daniel CN, Singh S. Caesarean delivery: An experience from a tertiary institution in North Western Nigeria. Niger J Clin Pract. 2016;19(1):18-24.

18. Okunade KS, Okunola H, Oyeneyin L, HabeebAdeyemi FN. Cross-sectional study on the obstetric performance of primigravidae in a teaching hospital in Lagos, Nigeria. Niger Med J. 2016;57(5):303-6.

19. Bimbola KO. Obstructed labour: The main cause of vesico-vaginal fistula-Review of literature. EJRMS. 2014;2(1):1-7.

20. Kabakyenga J, Östergren PO, Turyakira E, Mukasa $\mathrm{PK}$, Petterson KO. Individual and health facility factors and the risk for obstructed labour and its adverse outcomes in south-western Uganda. BMC Pregnancy Childbirth. 2011;11(1):73.

Cite this article as: Ubom AE, Ijarotimi OA, Ogunduyile IE, Omilakin A, Nyeche S, Igbodike EPet al. Obstructed labour in a Nigerian tertiary health facility: a mixed-method study. Int J Reprod Contracept Obstet Gynecol 2021;10:2937-43. 